\title{
MODEL PEMBERDAYAAN EKONOMI MUALAF OLEH LEMBAGA AMIL ZAKAT: STUDI KASUS LAZ BMH PADA MUALAF SUKU TENGGER ${ }^{1)}$
}

\author{
Andika Ramadhanu \\ Mahasiswa Program Studi Ekonomi Islam-Fakultas Ekonomi dan Bisnis-Universitas Airlangga \\ Email: andika.ramadanu-12@feb.unair.ac.id
}

Tika Widiastuti

Departemen Ekonomi Syariah-Fakultas Ekonomi dan Bisnis-Universitas Airlangga

Email: tika.widiastuti@feb.unair.ac.id

\begin{abstract}
:
The study aims to understand the economic empowerment model of Muslim converts by amil zakat institution, taking what LAZ BMH has done to Tengger's Muslim converts as study case. Using qualitative descriptive approach with study case, the data collected through interviews with empowerment manager of BMH, Tengger's Muslim converts, and the preacher, direct participatory observation, as well as documentation. In validating the data, this study uses data triangulation technique before analyzing through data reduction, presentation, and conclusion. The results of this study indicate that BMH has a role in economic empowerment of Tengger's Muslim converts. It could be seen through their resurgent Islamic rituals, still-good relationships with their neighbors, and their success in making ends meet. Not only economically empowered, Tengger's Muslim converts also become religiously stronger.
\end{abstract}

Keywords : Tengger's Muslim Converts, BMH Amil Zakat Institution, Economic Empowerment

\section{Pendahuluan}

\section{Latar Belakang}

Zakat merupakan salah satu pilar terpenting dalam tegaknya Islam. Dimana, empat pilar yaitu bersyahadat, shalat, shaum, dan haji merupakan hubungan dengan Allah sedangkan zakat merupakan pilar yang berhubungan dengan manusia khususnya dalam dimensi ekonomi.

Sepanjang sejarah islam, zakat telah memegang peranan penting dalam memegang peranan penting dalam mengambangkan peradaban bangsa yang memiliki peran strategis dalam kegiatan ekonomi, sosial, dan kebudayaan. Kehadiran dana sosial yang khas dalam sistem ekonomi islam, seperti zakat menjadi sistem jaring pengamanan sosial (social safety net), sehingga melalui hal ini maka tercipta suatu keseimbangan ekonomi dalam masyarakat sebab harta tidak akan berputar kepada orang-orang tertentu saja.

Indonesia merupakan negara dengan penduduk Muslim terbesar di dunia. Menurut Badan Pusat Statistik, penduduk Indonesia pada saat sensus penduduk 2010 berjumlah 237 juta jiwa dan $87,18 \%$ dari penduduk Indonesia beragama Islam, yaitu sekitar 207,2 juta jiwa. Banyaknya jumlah penduduk Muslim Indonesia membuat Indonesia memiliki potensi besar dalam dana zakat.

Potensi dana zakat menurut Wibisono (2015: 70) dihitung dari $1,7 \%$ dari PDB Indonesia. pada tahun 2011 dan 2012

1) Jurnal ini merupakan bagian dari skripsi dari Andika Ramadhnu, NIM: 041211432038, yang diuji pada tanggal 08 Agustus 2016 
jumlah PDB Indonesia berjumlah 7.006,7 Triliun dan 8.089,7 Triliun sehingga potensi zakat pada tahun 2011 dan 2012 berpotensi berjumlah 119,1 Triliun dan 137,5 Triliun.

Pemerintah Indonesia melakukan amandemen Undang-Undang no. 38 tahun 199 menjadi Undang-Undang no. 23 tahun 2011 agar dapat merealisasikan potensi besar zakat yang dimiliki Indonesia. UU no. 23 tahun 2011 mengamantakan pengelolaan zakat dikelola secara terpusat.

Lembaga yang ditugaskan dalam melaksanakan pengelolaan zakat secara terpusat yaitu Badan Amil Zakat Nasional (BAZNAS). Menurut UU No. 23 tahun 2011 BAZNAS dalam menjalan tugas dan fungsinya dibantu oleh Lembaga Amil Zakat yang dibentuk oleh masyarakat.

LAZ dalam menjalankan fungsi nya untuk mendayagunakan zakat di Indonesia. LAZ membuat berbagai program kepada delapan asnaf yang berhak menerimanya. delapan asnaf itu adalah fakir, miskin, amil, mualaf, riqab, gharim, fi sabilillah, dan ibnu sabil.

Pendayagunaan Zakat oleh LAZ dilakukan melalui berbagai program yang salah satunya yaitu pemberdayaan masyarakat secara ekonomi. zakat yang digunakan dalam program pemberdayaan masyarakat akan menciptakan pembangunan ekonomi yang tidak lepas dari nilai-nilai sosial masyarakat.

\section{Program}

pemberdayaan

masyarakat oleh LAZ kurang merata terhadap delapan asnaf khususnya kepada mualaf. Menurut Ketua divis advokasi Dompet Dhuafa Sabeth Abilawa dalam Republika.co.id

Ketua Divisi Advokasi Dompet Dhuafa Sabeth Abilawa mengakui, para mualaf memang belum banyak tersentuh program pemberdayaan dari amil zakat. la mengatakan jumlah mualaf tidak sebanyak jumlah kalangan miskin yang biasa ditangani badan-badan pengelola zakat. "Kami memahami hal itu karena jumlah mualaf sedikit," kata Sabeth. Sabeth mengatakan, batuan ekonomi kepada mualaf tidak bersifat mendesak. Sebab, menurutnya, mayoritas mualaf memiliki kemampuan ekonomi. Bantuan untuk mualaf lebih ditekankan kepada penguatan akidah dan pendalaman ilmu agama Islam. Untuk itu, Sabeth berharap, organisasi pemberdayaan mualaf mengintensifkan sisi edukasi bagi mualaf. "Kalau secara ekonomi, mualaf kebanyakan orang mampu. Masalah mereka di edukasi soal keislaman," vjar Sabeth.

Pendapat di atas merupakan bukti bahwa bukti LAZ di Indonesia masih belum optimal dalam memberdayakan mualaf. Padahal mualaf merupakan salah satu 8 asnaf yang wajib diberi zakat.

Salah satu LAZ yang perhatian dalam pemberdayaan mualaf adalah Lembaga Amil Zakat (LAZ) Baitul Maal Hidayahtullah (BMH). perhatian LAZ BMH dalam pemberdayaan asnaf mualaf tergambarkan dari berbagai program yang dijalan kan LAZ BMH. salah satu program yang dijalankan oleh LAZ BMH untuk pemberdayaan mualaf yaitu program pemberdayaan mualaf Tengger.

Program pemberdayaan mualaf Tengger dijalankan oleh LAZ BMH 
Surabaya. LAZ BMH surabaya merupakan salah satu cabang LAZ BMH yang beroperasi di kota Surabaya dan sekitarnya.

Program pemberdayaan mualaf Tengger dilakukan karena mayoritas masyarakat suku Tengger masih menganut agama Hindu serta kepercayaan nenek moyang mereka. Kondisi masyarakat suku Tengger jauh tertinggal dari kota. insfrastruktur tidak memadai seperti jalan belum beraspal sehingga hanya bisa diakses menggunakan kuda, televisi, radio, dan listrik belum masuk ke wilayah suku Tengger.

LAZ BMH Surabaya menggunakan pendekatan dakwah yang mudah diterima oleh masyarakat Tengger yang notabene mayoritas masih menganut agama Hindu. Pendekatan yang sukses tersebut tergambarkan dengan banyaknya masyarakat suku Tengger dari berbagai kalangan yang bersyahadat untuk masuk Islam.

Tujuan program pemberdayaan mualaf suku Tengger ada untuk memperkuat akidah mualaf suku Tengger agar tidak keluar dari agama Islam. Selain itu program tersebut bertujuan untuk meningkatkan kesehjateraan mualaf suku Tengger secara ekonomi. sehingga semakin kuat akidah mualaf suku Tengger dan semakin sejahtera maka dakwah untuk masyarakat Tengger yang belum menjadi mualaf akan semakin luas.

Berdasarkan uraian latar belakang yang telah dijelaskan di atas, maka peneliti merumuskan masalah penelitian yang diangkat dalam penelitian ini sebagai berikut. Bagaimana model pemberdayaan mualaf oleh Lembaga Amil Zakat: studi kasus LAZ BMH pada mualaf suku Tengger

Adapun tujuan penelitian ini untuk mengetahui dan menganalisa model pemberdayaan mualaf oleh LAZ mengambil studi kasus LAZ BMH pada mualaf suku Tengger. Menganalisa dampak dari penguatab ekonomi terhadap kehidupan sosial dan ekonomi mualaf sukU Tengger oleh LAZ BMH.

\section{LANDASAN TEORI}

Zakat merupakan salah satu rukun Islam yang menjadi pilar bangunan Islam. Sebagaiman sabda nabi.

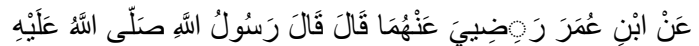

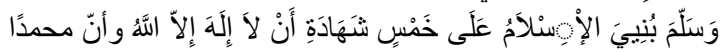

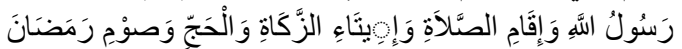
tentang pengelolaan zakat mengartikan zakat sebagai harta yang wajib dikeluarkan oleh seorang Muslim maupun badan usaha untuk diberikan kepada yang berhak menerimanya sesuai dengan syariat Islam.

Zakat menurut bahasa berarti tumbuh dan berkembang. Setiap sesuatu yang berkembang dan bertambah 
bernama zakat. Sedangkan menurut syara' beribadah kepada Allah menggunakan hartanya dengan cara mengeluarkan hartanya sesuai dengan syara' yang berlaku unutk diberikan kepada kelompok yang berhak menerima sesuai syara'. (Al Utsaimin, 2012: 45)

Definisi zakat dari sudut pandang ekonomi menurut Ryandono (2008: 6) zakat adalah merupakan salah satu cara mendistribusikan kekayaan (harta) dalam perekonomian khususnya dari orang kaya kepada orang miskin. Zakat mampu untuk mengerakkan perekonomian dengan cepat, terbangun persaudaraan diantara orang kaya dan miskin sehingga akan menipiskan kesenjangan ekonomi antara orang miskin dengan orang kaya. Demikian zakat menjadi pengontrol perekonomian agar mencapai falah (kesehjateraan lahir, batin, dunia, dan akhirat).

Menurut Ibnul Qayyim dalam Hafidhuddin (2004: 28) pada dasarnya ada empat jenis harta yang dikenai zakat yaitu tanam-tanaman dan buah-buahan, hewan ternak, emas dan perak, serta harta perdagangan. empat jenis inilah yang paling banyak beredar di kalangan umat manusia, dan kebutuhan kepadanya merupakan hal yang terpenting (dharuri).

Orang-orang yang berhak menerima zakat terdapat pada QS Attaubah ayat 60. Orang yang berhak meneima zakat yaitu fakir, miskin, amil, mualaf, riqab, gharim, fil sabilillah, dan ibnu sabil.
Menurut Qardawi (2011: 563) yang dimaksud dengan golongan mualaf adalah mereka yang diharapkan keyakiinan hatinya dapat bertambah terhadap islam, atau tidak memiliki niat jahat atas kaum Muslimin serta diharapkan adanya kemanfaatan mereka dalam membela kaum Muslimin dari musuh. Sedangkan menurut Sabiq (2008: 145)

mualaf adalah orang yang dilunakkan hatinya agar mereka tertarik pda agama islam karena belum keimanan mereka belum mantap, atau untuk menghindari petaka yang mungkin mereka lakukan terhadap kaum Muslimin, atau mengambil keuntungan yang mungkin dimanfaatkan untuk kepentingan mereka.

Amil zakat secara tekstual terdapat dalam Q.S At-Taubah ayat 60, memiliki peran yang sangat penting baik dalam pengumpulan dan pendistribusian zakat. (Hafidhuddin, 2004: 125).

Saat ini dapat dipahami bahwa amil zakat bukan orang-perseorangan melainkan badan atau lembaga. Undang-undang No. 23 tahun 2011 tentang pengelolaan zakat menetapkan bahwa BAZNAS (Badan Amil Zakat Nasional) merupakan lembaga yang berwenang melakukan tugas pengelolaan zakat secara nasional. Pada sisi yang lain masyarakat dapat membentuk Lembaga Amil Zakat (LAZ). Pada bagian keempat Lembaga Amil Zakat pasal 17 disebutkan bahwa:

Untuk membantu BAZNAS dalam pelaksanaan pengumpulan, 
pendistribusian, dan pendayagunaan zakat, masyarakat dapat membentuk LAZ, oleh karena itu lembaga zakat secara umum dapat dibedakan menjadi dua yaitu BAZ (Badan Amil Zakat) dan Non-Baz atau disebut dengan LAZ (Lembaga Amil Zakat).

Konsep

pemberdayaan

masyarakat mencakup pembangunan masyarakat (community development) dan pembangunan yang bertumpu pada masyarakat

(community-based

development). Dalam memahami hal tersebut terlebih dahulu memahami mengenai keberdayaan dan pemberdayaan masyarakat. Keberdayaan masyarakat merupakan unsur-unsur yang dapat digunakan masyarakat untuk bertahan, dan dalam arti dinamis dapat mengembangkan diri untuk mencapai kemajuan. Sedangkan, memberdayakan masyarakat adalah upaya unutk meningkatkan kehidupan masyarakat dari perangkap kemiskinan dan keterbelangkangan menuju masyarakat yang maju. (Mardikanto dan Soebiato, 2015: 40)

Instrumen

pemberdayaan

masyarakat dalam islam yaitu menggunakan zakat. Zakat mampu mengurangi kesenjangan antara orang kaya dan orang miskin. Zakat dapat meningkatkan kemampuan membeli barang dan jasa orang miskin dari tidak mampu membeli menjadi mampu membeli barang dan jasa, sehingga hal ini dapat meningkatkan permintaan barang dan jasa. Kesimpulannya yaitu zakat mampu meningkatkan konsumi dan mendorong pertumbuhan ekonomi. (Ryandono, 2008: 26)

Menurut Tjiptoherianto (1988: 10) seseorang dapat dikatakan terberdaya jika telah memenuhi indikator-indikator pemberdayaan sebgai berikut:

a) Keimanan yaitu naiknya ketakwaan seorang terhadap Allah SWT yang tercermin dari keaktifannya beribadan serta menjalankan kegiatan-kegiatan dakwah Islam

b) Kemampuan membeli, yaitu kemampuan individu untuk membeli barang-barang kebutuhan keluarga sehari-hari serta kebutuhan dirinya seperti makan dan minum serta pendidikan

c) Kemampuan membeli barang kebutuhan tambahan, yaitu kemampuan individu untuk memberli barang-barang sekunder atau tersier, seperti lemari pakaian, TV, radio, Koran, majalah, pakaian, dan kendaraan bermotor

d) Jaminan ekonomi dan kontribusi terhadap keluarga, yaitu seperti memiiki rumah, tanah, asset produktif, tabungan karena spek-aspek tersebut merupakan hal yang dibutuhakan keluaraga. Seseorang dianggap terberdaya jika ia memiliki atau dapat memenuhi aspek-aspek tersebut secara sendiri atau terpisah dari pasangannya

e) Hubungan bermasyarakat, yaitu keaktifan seseorang dengan menjalin atau mengikuti kegiatan bermasyarakat di lingkungan sekitar 
Ramadhanu, et al/Jurnal Ekonomi Syariah Teori dan Terapan Vol. 4 No. 4 April 2017: 281-296; MODEL PEMBERDAYAAN EKONOMI MUALAF OLEH LEMBAGA AMIL ZAKAT: STUDI KASUS LAZ BMH PADA MUALAF SUKU TENGGER

atau terlibat kegiatan dalam perannya sebagai warga negara

\section{METODOLOGI PENELITIAN}

Penelitian ini menggunakan pendekatan kualitatif. Pendekatan kualitatif dimana peneliti menjadi instrumen kunci dalam pengumpuan, analisis, serta interpretasi data. Strategi dalam penelitian ini menggunakan studi kasus. Jenis studi kasus yang digunakan dalam penelitian ini adalah studi kasus deskriptif yang bertujuan unutk memberikan gambaran secara mendetail tentang latar belakang, sifat-sifat, serta karakter-karakter yang khas dari suatu kasus.

\section{Ruang Lingkup Penelitian}

Penelitian yang dimaksud adalah untuk menjawab rumusan masalah penelitian yaitu bagaimana peran lembaga amil zakat baitul maal hidayatullah dalam pemberdayaan ekonomi mualaf Tengger?. Rumusan masalah tersebut menjadi acuan peneliti dalam menentukan ruang lingkup penelitian ini, yang dijadikan acuan dengan batasan atau ruang lingkup penelitian Penelitian ini difokuskan pada program pemberdayaan mualaf Tengger yang diselenggarakan oleh Baitul Maal Hidayatullah dan mualaf yang masuk Islam berasal dari program dakwah LAZ BMH serta mualaf yang masuk Islam oleh orang pertama masuk Islam di desa Argosari

\section{Jenis dan Sumber Data}

Data yang digunakan dalam penelitian ini adalah hasil penggabungan antara data primer dan data sekunder.

Data primer yang digunakan dalam skripsi ini adalah data hasil wawancara dan observasi lapangan di desa Argosari dan data sekunder yang digunakan adalah dokumentasi program pemberdayaan mualaf Tengger.

\section{Teknik Pengumpulan Data}

Pengumpulan data primer dalam penelitian ini dilakukan dengan cara wawancara kepada informan dan juga observasi secara langsung pada manjaer pendayagunaan zakat LAZ BMH, mualaf suku Tengger dan Da'i. Pengumpulan data sekunder dilakukan dengan cara dokumentasi kegiatan program pemberdayaan mualaf suku Tengger.

\section{Teknik Analisis}

Dalam penelitian ini, setelah dilakukan pengumpulan data, maka data tersebut dianalisis untuk mendapatkan kesimpulan. Bentuk anaisis data yang digunakan adalah sebagai berikut:

a) Reduksi Data

b) Penyajian data

c) Menarik Kesimpulan

\section{IV, HASIL DAN PEMBAHASAN}

Objek Penelitian yang digunakan dalam penelitian ini adalah Lembaga Amil Zakat (LAZ) Baitul Maal Hidayahtullah (BMH) dan Desa Argosari kecamatan Senduro Kabupatan Lumajang.

Baitul Maal Hidayahtullah atau yang biasa dikenal dengan nama $\mathrm{BMH}$ adalah Lembaga Zakat yang bergerak dalam pengimpunan dana zakat, infaq, 
sedekah, kemanusiaan, dan Corporate Social Responsibility perusahaan. Baitul Maal Hidayahtullah juga melakukan pendistribusian melalui program pendidikan, dakwah, sosial, dan ekonomi secara nasional.

Program-Program yang dijalankan oleh LAZ BMH meliputi program pendidikan, dakwah sosial, dan ekonomi. pada tahun 2016 ini LAZ BMH menjalankan program seperti Program Da'i Tangguh,Program mandiri terdepan, Program Senyum Anak Indonesia, dan Program Solidaritas Siaga Bencana.

Desa Argosari adalah salah satu desa dari 12 desa di kecamatan Senduro, kabupaten Lumajang, provinsi Jawa Timur. Desa Argosari memiliki luas wilayah seluas 1.274.585 Ha. Letak desa Argosari langsung berbatasan dengan hutan negara dan Gunung Bromo serta letak wilayah desa Argosari berada di kawasan lereng Gunung Semeru.

Desa Argosari pada tahun 2014 memiliki jumlah penduduk sebanyak 960 KK atau sebanyak 3.425 Jiwa yang terdiri dari laki-laki berjumlah 1.726 Jiwa sedangkan perempuan berjumlah 1.699 Jiwa. Sebanyak $60 \%$ dari jumlah penduduk desa Argosari memeluk agama Hindu dan sebanyak $40 \%$ dari jumlah penduduk desa Argosari memeluk agama Islam, jadi berdasarkan data tersebut mayoritas masyarakat desa Argosari memeluk agama Hindu dan pemeluk agama Islam masih minoritas.

Kualitas Sumber daya Manusia (SDM) penduduk desa Argosari sangat rendah ini terlihat dari Menurut RPJM desa tahun 2015-2020. Penduduk Desa yang hanya lulusan SD berjumlah 1276 Jiwa. Penduduk desa ada juga yang hanya IUlusan PAUD

dan TK yaitu berjumlah 32 Jiwa dan 126 jiwa sedangkan penduduk yang lulus SLTP berjumlah 96 jiwa. Penduduk Desa yang Iulusan SLTA hanya berjumlah 89 Jiwa. Pada tabel di atas juga terlihat bahwa tamatan pendidikan tinggi jumlahnya sangat sedikit sekali ini terlihat bahwa lulusan D-3 hanya 2 jiwa dan Iulusan strata 1 atau biasa disebut S-1 hanya berjumlah 8 jiwa.

Kekuatan ekonomi desa Argosari terletak pada sektor pertanian dan sektor pariwisata. Sektoer pertanian telihat dari menurut RPJM desa tahun 2015-2020 pada 2014 pertanian Desa Argosari bergerak pada jenis tanaman kentang, bawang, kubis, dan wortel. bawang menjadi komoditas terbanyak yang dihasilkan desa Argosari yaitu sebanyak 1 ton/hektar dengan luas area yang digunakan seluas 358 hektar sehingga bawang yang dihasilkan desa Argosari sebanyak 358 ton. Komoditas terbanyak kedua yaitu kubis sebanyak 2,5 ton/hektar dengan luas yang digunakan 129 hektar sehingga kubis yang dihasilkan sebanyak 322,5 ton. Selanjutnya komoditas terbanyak ketiga yaitu kentang sebanyak 1,5 ton/hektar dengan luas lahan yang digunakan 105 hektar maka kentang yang dihasilkan sebanyak 157,5 ton. Komoditas pertanian terakhir yang dihasilkan desa Argosari yaitu wortel sebanyak 1,5 ton/hektar 
dengan luas lahan yang digunakan 12 hektar sehingga menghasilkan wortel sebanyak 18 ton

Selain sektor pertanian yang besar desa Argosari juga memiliki sektor pariwisata yang besar ini karena desa Argosari berbatasan langsung dengan Hutan negara dan gunung Bromo serta berada pada kawasan lereng gunung Semeru membuat desa Argosari berada di ketinggian $2900 \mathrm{Mdpl}$ yang menjadikan desa Argosari memiliki panorama pemandangan yang indah dari bukitbukit, dapat melihat gunung Bromo serta dapat melihat Gunung Semeru. Panorama pemandangan yang indah tersebut membuat desa Argosari dikenal sebagai B-29 yang berarti bukit di ketinggian $2900 \mathrm{Mdpl}$ dan dikenal juga sebagai negeri di atas awan

Desa Argosari tidak memiliki infrastruktur jalan yang baik dengan kondisi topografi desa Argosari yang berbukit-bukit dan curam membuat kenyamanan dan mobilisasi penduduk desa Argosari tidak berjalan dengan baik. kenyamanan dan mobilisasi penduduk desa Argosari yang tidak berjalan dengan baik menyebabkan pada sektor pertanian dan sektor pariwisata desa Argosari tidak berkembang dan cederung stagnan. Kendala terbesar yang di hadapi desa Argosari dalam mengembangkan dan memajukan ekonomi desa di sektor pertanian dan sektor pariwisata adalah bencana erupsi gunung atau yang sering disebut bencana gunung meletus. Desa Argosari merupakan desa rawan bencana erupsi gunung Semeru dan gunung Bromo karena letak desa Argosari dekat dengan kedua gunung tersebut. dampak dari erupsi gunung pada sektor pertanian adalah kegagalan panen karena debu vulkanik yang dikeluarkan atau yag dihasilkan dari erupsi gunung membuat tanaman di pertanian membusuk sehingga dengan membusuknya tanaman pertanian mengakibatkan kegagalan panen bagi masyarakat desa Argosari sehingga roda ekonomi masyarakat desa Argosar berhenti. Dampak erupsi gunung pada sektor pariwisata adalah menurunnya kunjungan wisatawan yang berkunjung ke wisata desa Argosari seperti B-29 maupun B-30 dan merusak berbagai fasilitas yang dapat menunjang kemajuan dari wisata desa Argosari.

Subjek penelitian yang digunakan dalam penelitian ini berjumlah 11 Informan yang terdiri dari tujuh Mualaf suku Tengger, tiga Da'i, dan satu manajer Pendayagunaan LAZ BMH. tujuh mualaf tersebut terdiri dari Astotomo, Misman, Sukardi, Wagiman, Sunarsan, Sukaryo, dan Paito Amorogo. tiga Da'i yaitu terdiri dari Mujtahid Ja'far, Warsito, dan Bukhori Muslim. satu manajer pendayagunaan bernama Eko Muliansyah.

Pemberdayaan mualaf suku Tengger khususnya di desa Argosari memerlukan Sinergistas dan sinkronisasi antar Stakeholder yang memiliki kepentingan di desa Argosari. sinergistas dan sinkronisasi dari masing-masing stakeholder memiliki fungsi dan peran 
penting dalam pemberdayaan mualaf Tengger. Selain itu, adanya sinergisitas antar Stakeholder untuk mewujudkan dinamisasi pemberdayaan mualaf Tengger yang ideal untuk saling melengkapi agar program pemberdayaan mualaf Tengger berjalan dengan lancar.

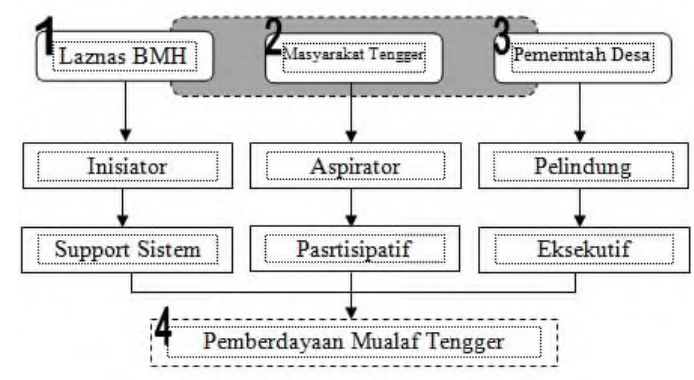

Sumber: Hasil Penelitian (Diolah)

Gambar 1.

Sinergisitas Stakeholder dalam

Pemberdayaan Mualaf Tengger

Pemberdayaan Mualaf Tengger di Desa Argosari memiliki tiga stakeholder yang memiliki peran dan fungsi yang penting dalam menjalankan pemberdayaan mualaf. Pada gambar 1 di atas terdapat 3 stakeholder yaitu LAZ BMH, Masyarakat Tengger, dan Pemerintah Desa Argosari. 1) Lembaga Amil Zakat Nasional (LAZNAS) Baitul Maal Hidayahtullah (BMH) menjadi stakeholder pertama dan utama dalam pemberdayaan mualaf di desa Argosari ini. peran LAZNAS BMH sebagai inisiator merupakan konseptor pertama pemberdayaan mualaf suku Tengger dan LAZNAS BMH juga menjadi penggerak pertama yang akan mengandeng stakeholder yang lain untuk bersamasama untuk memberdayakan mualaf suku Tengger. fungsi dari LAZNAS BMH sebagai
Support Sistem, yaitu setiap program pemberdayaan yang mempertimbangkan dari aspek aspirasi dan kebutuhan mualaf Tengger seluruhnya dibiayai oleh LAZNAS BMH

2) Stakeholder yang kedua adalah masyarakat Tengger, masyarakat Tengger merupakan stakeholder yang penting karena masyarakat Tengger merupakan subjek pemberdayaan mualaf yang akan bahu membahu bersama LAZNAS BMH dan pemerintah Desa dalam menjalankan pembinaan dan pemberdayaan mualaf tersebut baik dalam dalam tataran konseptual dan implementasi serta mualaf Tengger merupakan bagian yang tidak terpisahkan dari masyakat Tengger sehingga dalam menjalankan pembinaan dan pemberdayaan mualaf, masyarakat Tengger memiliki peranan penting. masyarakat sebagai aspirator memegang peranan penting dalam program pemberdayaan mualaf Tengger, karena mualaf Tengger sebagai subjek dari pemberdayaan dan mualaff Tengger meupakan bagian dari msyarakat Tengger maka setiap langkah mulai dari perumusan konsep program, implementasi program, dan evaluasi program harus mempertimbangkan aspirasi dari masyarakat Tengger agar program yang dijalankan LAZNAS BMH di desa Argosari dapat berjalan dengan baik. fungsi masyarakat Tengger sebagai pasrtisipatif memberikan kontribusi yang nyata dalam program pemberdayaan mualaf, karena masyarakat Tengger merupakan pelaku sosial maka masyarakat Tengger menjadi 
power untuk mensukseskan program pemberdayaan mualaf di desa Argosari.

3) Stakeholder yang ketiga adalah pemerintah desa, pemerintah desa dibutuhkan dalam pemberdayaan mualaf Tenggerr ini akrena sebagai otoritas regulasi yang memberikan izin kegiatan di desa Argosari dan paling mengerti dengan kondisi sosial dan geografis desa Argosasi. Peran pemerintah Desa sebagai pelindung program pemberdayaan yang dijalankan oleh LAZNAS BMH. fungsi pemerintah desa sebagai eksekutif yang menjalankan perekonomian desa Argosari dari peningkatan hasil pemberdayaan mualaf Tengger agar perekonomian desa Argosari Khususnya mualaf Tengger lebih suistainable

Sinergisitas stakeholder untuk mensukses dan melancarkan jalannya program pemberdayaan mualaf Tengger di desa Argosari telah terwujud sehingga Lembaga Amil Zakat Nasional (LAZNAS) Baitul Maal Hidayahtullah (BMH) yang menjalankan pemberdayaan dapat melaksanakan tugas nya dengan baik hingga saat ini. LAZNAS BMH dalam melaksanakan pembinaan dan pemberdayaan menggunakan pendekatan silahturahmi untuk mengenal lebih dalam masyarakat Tengger yang notabene merupakan mayoritas beragama Hindu serta memenuhi kebutuhan yang dibutuhkan dari masyarakat Tengger agar diterima dengan baik oleh masyarakat Tengger dan saat melaksanakan program dapat berjalan dengan baik. Berikut akan dijelaskan model pemberdayaan mualaf Tengger yang dilakukan oleh LAZNAS BMH saat melakukan pendekatan, pembinaan,

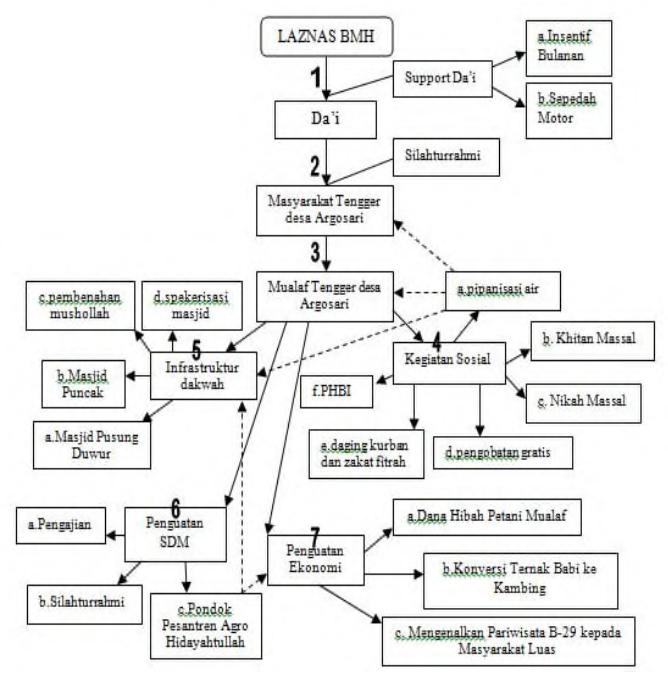

Sumber: Hasil Penelitian (Diolah)

Gambar 2.

Model Pemmberdayaan Mualaf Tengger di Desa Argosari

Pada gambar 2 di atas Lembaga Amil Zakat Nasional (LAZNAS) Baitul Maal Hidayahtullah (BMH) dalam melakukan pembinaan dan pemberdayaan mualaf Tengger di desa Argosari mengutus Da'i unutk menjalankan beberapa program seperti di bidang sosial, ekonomi, dakwah, dan peningkatan Sumber Daya Manusia (SDM) mualaf Tengger. Berikut ini kinerja dari Model pemberdayaan mualaf Tengger:

1)Langkah awal LAZNAS BMH dalam melakukan pemberdayaan mualaf Tengger di desa Argosari adalah mengutus Da'i tinggal di desa Argosari untuk melakukan pendekatan kepada masyarakat Tengger di desa Argosari serta melakukan pembinaan dan pemberdayaan mualaf Tengger. Da'i 
dalam membina dan memberdayakan mualaf Tengger di desa Argosari mengalami banyak tantangan karena kondisi alam desa Argosari yang berat mulai dari kondisi suhu desa Argosari yang yang sangat dingin dan kondisi medan jalan yang berbukit-bukit serta sebagian jalan desa yang rusak.

LAZNAS BMH mengatasi tantangan yang dihadapi Da'i dalam membina dan memberdayakan mualaf Tengger desa Argosari melalui support kepada Da'i. support Da'i ini bertujuan untuk membantu dan memperkuat Da'i agar dalam menjalankan pembinaan dan pemberdayaan mualaf, Da'i semangat dalam mengatasi tantangan dakwah di desa Argosari. Support Da'i yang dilakukan oleh LAZNAS BMH ada dua macam yaitu: a) Intensif Bulanan berupa vang tunai sebesar 1 juta rupiah, b) diberi fasilitas sepedah motor.

2) pada tahap selanjutnya LAZNAS BMH melalui Da'i yang bertugas di desa Argosari melakukan pendekatan kepada masyarakat Tengger desa Argosari. mendekati masyarakat desa Argosari merupakan faktor terpenting dalam suksesnya pemberdayaan mualaf Tengger ini karena mualaf Tengger merupakan bagian dari masyarakat Tengger desa Argosari.

3) Da'i telah melakukan pendekatan dengan silahturrahim ke masyarakat Tengger desa Argosari sehingga masyarakat Tengger desa Argosari menerima dan tertarik program pembinaan dan pemberdayaan mualaf
Tengger serta sedikit demi sedikit masyarakat desa Argosari mulai masuk agama Islam.

4) program yang dijalankan LAZNAS BMH setelah diterima masyarakat Tengger desa Argosari dan sedikit demi sedikit masyarakat Tengger menjadi mualaf. LAZNAS BMH mengadakan kegiatan sosial untuk mualaf dan masyarakat Tengger desa Argosari. tujuan diadakan kegiatan sosial ini bertujuan unutk memenuhi kebutuhan sosial mualaf dan saling memperkenalkan antar mualaf agar mualaf yang menjadi minoritas di desa Argosari menjadi semangat untuk memperdalam ilmu Islam karena mualaf Tengger merasa banyak teman dalam memperdalam ilmu agama Islam. Selain itu tujuan dari kegiatan sosial tersebut untuk lebih mengenalkan Islam kepada masyarakat Tengger sehingga membuat semakin banyak masyarakat Tengger desa Argosari tertarik belajar Islam pada akhirnya banyak masyarakat Tengger desa Argosari masuk Islam dan menjadi mualaf.

Kegiatan sosial yang dijalankan oleh LAZNAS BMH adalah a) pipanisasi, b) Khitan Massal, c) Nikah Massal, d) pengobatan gratis, e) daging kurban dan zakat fitrah, f) PHBI.

5) LAZNAS BMH selain mengadakan kegatan sosial untuk memperkuat mualaf dan mendekati masyarakat Tengger desa argosari secara intensif, LAZNAS BMH juga memperkuat dakwah Da'i yang bertugas di desa Argosari dengan membangun infarstruktur dakwah. Infrastruktur dakwah 
ini berfungsi selain untuk memperkuat dakwah juga untuk menyebarkan syiar Islam lebih luas di desa Argosari. LAZNAS $\mathrm{BMH}$ memperkuat infrastruktur dakwah seperti a) Pembangunan Masjid Pusung Duwur, b) Pembangunan Masjid Puncak, C) Pembenahan Mushollah, dan d) speakerisasi Masjid.

6) Langkah berikutnya dalam pemberdayaan mualaf Tengger desa Argosari adalah penguatan Sumber Daya Manusia (SDM) mualaf. Seperti yang telah dijelaskan dalam gambaran umum desa Argosari bahwa kualitas SDM desa Argosari sangat rendah, hal tersebut dapat dilihat bahwa mayoritas masyarakat Tengger desa Argosari hanya Iulusan SD sehingga kondisi tersebut juga berpengaruh kepada mualaf dalam menjalankan program pemberdayaan mualaf. Kondisi SDM mualaf yang rendah sering membuat apa yang sudah direncakan oleh Da'i tidak berjalan dengan lancer sesuai yang Da'i arahkan sehingga untuk mensukseskan pemberdayaan program pemberdayaan mualaf Tengger desa Argosari, LAZNAS BMH melalui Da'i melakukan penguatan SDM mualaf Tengger desa argosari.

Program penguatan SDM mualaf sukU Tengger seperti a) melalvi pengajian yang diadakan oleh Da'i, b) Da'i bersilahturrahim kepada mualaf-mualaf suku Tengger, dan c) pembangunan pondok pesantrean agro hidayahtullah.

7) Program selanjutnnya yang dijlankan oleh LAZNAS BMH melalui Da'i yang bertugas di desa Argosari adalah program penguatan ekonomi mualaf. Program penguatan ekonomi mualaf merupakan program inti dari program pemberdayaan mualaf di desa Argosari. program penguatan ekonomi ini bertujuan untuk memperbaiki ekonomi dari mualaf Tengger dan memperkuat kelslaman mualaf melalui ekonomi karena faktor ekonomi merupakan faktor terkuat seseorang bisa meninggalkan agama Islam maka LAZNAS BMH melalui program penguatan ekonomi meminimalisair kejadian mualaf suku Tengger kemabli ke agamanya yang dahulu. Program penguatan yang dijalankan oleh LAZNAS BMH seperti a) Dana Hibah Petani Mualaf suku Tengger, b) konversi ternak babi ke kambing, dan c) mengenalkan pariwisata B-29 kepada masyarakat luas.

Keberhasilan Lembaga Amil Zakat Nasional (LAZNAS) Baitul Maal Hidayahtullah (BMH) dalam melakukan pemberdayaan mualaf Tengger desa Argosari adalah terberdayanya mualaf Tengger desa Argosari. terberdayanya mualaf Tengger desa Argosari dapat dilihat dari aspek meningkatnya pendapatan mualaf Tengger dan mualaf Tengger semakin dekat kepada Allah SWT melalui ibadahnya yang semakin meningkat. LAZNAS BMH dalam melakukan pemberdayaan kepada mualaf Tengger sehingga keberhasilan pemberdayaan mualaf Tengger dilihat dari peningkatan pendapat mualaf Tengger dan mualaf Tengger semakin dekat kepada Allah melalui ibadahnya yang semakin meningkat. 
Peningkatan pendapatan mualaf Tengger desa Argosari dilihat dari prioritas konsumsi yang dilakukan oleh mualaf Tengger dari kebutuhan dharuriyat sampai tahsiniyat. Sedangkan mualaf Tengger dekat dengan Allah SWT dilihat dari meningkat atau tidak tidaknya mualaf Tengger beribadah. Berikut ini akan diuraikan mengenai indikator-indikator yang digunakan unutk mengukur keberhasilan peran LAZNAS BMH dalam pemberdayaan mualaf Tengger desa Argosari. Indikator yang dipakai yaitu indikator pemenuhan ibadah, indikator pemenuhan Hubungan Bertetangga, indikator pemenuhan makan dan minum, indikator pemenuha pendidikan, indikator pemenuhan tempat tinggal, indikator pemenuhan kendaraan, dan indikator pemenuhan rekreasi. Berikut ini indikatorindikator keberhasilan peran LAZNAS BMH dalam memberdayakan mualaf suku Tengger

Pemenuhan Ibadah

Tabel 1.

Pemenuhan Ibadah mualaf suku Tenager

\begin{tabular}{|c|c|c|c|c|}
\hline \multirow{2}{*}{ No } & \multirow{2}{*}{ Informan } & \multicolumn{2}{|c|}{ Tingkat Ibadah } & \multirow{2}{*}{ Keterangan } \\
\cline { 3 - 4 } & Asstotomo & Sebelum & Sesudah & \multirow{2}{*}{ Tidak Aktif } \\
\hline 1 & Misman & Tidak Aktif & Aktif & Meningkat \\
\hline 2 & Sukardi & Tidak Aktif & Aktif & Meningkat \\
\hline 3 & Wagiman & Tidak Aktif & Aktif & Meningkat \\
\hline 4 & Sunarsan & Tidak Aktif & Aktif & Meningkat \\
\hline 5 & Sukaryo & Tidak Aktif & Aktif & Meningkat \\
\hline 6 & Paito Amorogo & Tidak Aktif & Aktif & Meningkat \\
\hline 7 & \multicolumn{3}{|c}{} \\
\hline
\end{tabular}

Sumber: Data Primer (diolah)

Pada Tabel 1 di atas terlihat bahwa seluruh Informan yang merupakan mualaf suku Tengger mengalami peningkatan secara ibadah yang sebelum menjadi mualaf dan mendapatkan pemberdayaan dan pembinaan LAZNAS semua informan tidak aktif dalam ibadah sedangkan setelah menjadi mualaf dan mendapatkan pembinaan dan pemberdayaan LAZNAS BMH semua menjadi aktif untuk ibadah kepada Allah SWT.

Pemenuhan bertetangga

Tabel 2.

pemenuhan bertetangga mualaf suku Tengger

\begin{tabular}{|c|c|c|c|c|}
\hline \multirow{2}{*}{ No } & \multirow{2}{*}{ Informan } & \multicolumn{2}{|c|}{ Hubungan Bertetangga } & \multirow{2}{*}{ Keterangan } \\
\cline { 3 - 4 } & & Sebelum & Sesudah & \\
\hline 1 & Asstotomo & Baik & Baik & Terberdaya \\
\hline 2 & Misman & Baik & Baik & Terberdaya \\
\hline 3 & Sukardi & Baik & Baik & Terberdaya \\
\hline 4 & Wagiman & Baik & Baik & Terberdaya \\
\hline 5 & Sunarsan & Baik & Baik & Terberdaya \\
\hline 6 & Sukaryo & Baik & Baik & Terberdaya \\
\hline 7 & Paito Amorogo & Baik & Baik & Terberdaya \\
\hline
\end{tabular}

Sumber: Data Primer (diolah)

Pada tabel 2 di atas terlihat semua informan yang merupakan mualaf suku Tengger terberdayakan. Baik sebelum dan sesudah menjadi mualaf dan mendapatkan pemberdayaan dari LAZNAS BMH mualaf suku Tengger tetap berhubungan baik dengan tetangga karena berhubungan tetangga ini merupakan faktor terpenting dalam menjaga stabilitas kerukunan umat beragama di desa Argosari. jika kerukunan umat beragama terganggu mengakibatkan roda ekonomi terhenti.

pemenuhan kebutuhan makan dan minum

Pada Tabel 3 di bawah terlihat seluruh informan yang merupakan mualaf suku Tengger terberdaya semuanya karena mampu memenuhi kebutuhan makan dan minum setelah menjadi mualaf dan mendapatkan pemberdayaan dan pembinaan dari LAZNAS BMH. 
Tabel 3.

Pemenuhan kebutuhan makan dan minum Mualaf Suku Tengger

\begin{tabular}{|c|c|c|c|c|}
\hline \multirow{2}{*}{ No } & \multirow{2}{*}{ Informan } & \multicolumn{2}{|c|}{ Pemenuhan Makan dan Minum } & \multirow{2}{*}{ Keterangan } \\
\cline { 3 - 4 } & Astotomo & Sebelum & Sesudah & \\
\hline 1 & Murang & Mampu & Terberdaya \\
\hline 2 & Sukardi & Kurang & Mampu & Terberdaya \\
\hline 3 & Wagmpu & Mampu & Terberdaya \\
\hline 4 & Sagiman & Kurang & Mampu & Terberdaya \\
\hline 5 & Sunarsan & Kurang & Mampu & Terberdaya \\
\hline 6 & Sukaryo & Kurang & Mampu & Terberdaya \\
\hline 7 & Paito Amorogo & Mampu & Mampu & Terberdaya \\
\hline
\end{tabular}

Sumber: Data Primer: (diolah)

pemenuhan tempat tinggal mualaf suku Tengger

Tabel 4.

Pemenuhan Kebutuhan tempat tinggal mualaf suku Tengger

\begin{tabular}{|c|c|c|c|c|}
\hline \multirow{2}{*}{ No } & \multirow{2}{*}{ Informan } & \multicolumn{2}{|c|}{ Pemenuhan Tempat Tinggal } & \multirow{2}{*}{ Keterangan } \\
\cline { 3 - 4 } & Astotomo & Sebelum & Sesudah & \\
\hline 1 & Mampu & Mampu & Terberdaya \\
\hline 2 & Misman & Kurang & Mampu & Terberdaya \\
\hline 3 & Sukardi & Kurang & Mampu & Terberdaya \\
\hline 4 & Wagiman & Mampu & Mampu & Terberdaya \\
\hline 5 & Sunarsan & Kurang & Mampu & Terberdaya \\
\hline 6 & Sukaryo & Kurang & Mampu & Terberdaya \\
\hline 7 & Paito Amorogo & Mampu & Mampu & Terberdaya \\
\hline
\end{tabular}

Sumber: data primer (diolah)

Pada tabel 4 di atas terlihat seluruh informan yang merupakan mualaf suku Tengger terberdayakan karena mampu memenuhi kebutuhan tempat tinggal atau rumah setelah menjadi mualaf dan mendapatkan pemberdayaan serta pembinaan dari LAZNAS BMH.

Indikator pemenuhan kebutuhan pendidikan

Tabel 5.

Pemenuhan kebutuhan pendidikan mualaf suku Tengger

\begin{tabular}{|c|c|c|c|c|}
\hline \multirow{2}{*}{ No } & \multirow{2}{*}{ Informan } & \multicolumn{2}{|c|}{ Pemenuhan Pendidikan } & \multirow{2}{*}{ Keterangan } \\
\cline { 3 - 4 } & Sebelum & Sesudah & Tetap \\
\hline 1 & Astotomo & Tidak Lulus & Tidak Lulus & SD \\
& & SD & SD & \\
\hline 2 & Misman & Lulus SD & $\begin{array}{c}\text { Pendidikan } \\
\text { Pesantren }\end{array}$ & Meningkat \\
\hline 3 & Sukardi & $\begin{array}{c}\text { Tidak Lulus } \\
\text { SD }\end{array}$ & $\begin{array}{c}\text { Tidak Lulus } \\
\text { SD }\end{array}$ & Tetap \\
\hline 4 & Wagiman & Lulus SD & Lulus SD & Tetap \\
\hline 5 & Sunarsan & $\begin{array}{c}\text { Tidak Lulus } \\
\text { SD }\end{array}$ & $\begin{array}{c}\text { Tidak Lulus } \\
\text { SD }\end{array}$ & Tetap \\
\hline 6 & Sukaryo & $\begin{array}{c}\text { Tidak Lulus } \\
\text { SD }\end{array}$ & $\begin{array}{c}\text { Tidak Lulus } \\
\text { SD }\end{array}$ & Tetap \\
\hline 7 & Paito Amorogo & Lulus SR & Lulus SR & Tetap \\
\hline
\end{tabular}

Sumber: data primer (diolah)

Terlihat pada tabel 5 di atas terlihat bahwa hanya satu informan saja yang pendidikan nya meningkat setelah menjadi mualaf dan mendapatkan pemberdayaan dan pembinaan dari LAZNAS BMH. enam informan yang lain pendidikannya tetap walau sudah menjadi mualaf dan mendapatkan pemberdayaan serta pembinaan dari LAZNAS BMH

Pemenuhan Kebutuhan Kendaraan

Tabel 6.

Pemenuhan kebutuhan kendaraan mualaf suku Tengger

\begin{tabular}{|c|c|c|c|c|}
\hline \multirow{2}{*}{ No } & \multirow{2}{*}{ Informan } & \multicolumn{2}{|c|}{$\begin{array}{c}\text { Pemenuhan Kebutuhan } \\
\text { Kendaraan }\end{array}$} & \multirow{2}{*}{ Keterangan } \\
\cline { 3 - 4 } & & Sebelum & Sesudah & \\
\hline 1 & Astotomo & Tidak & Mampu & Terberdayakan \\
\hline 2 & Misman & Tidak & Mampu & Terberdayakan \\
\hline 3 & Sukardi & Tidak & Mampu & Terberdayakan \\
\hline 4 & Wagiman & - & - & - \\
\hline 5 & Sunarsan & - & - & - \\
\hline 6 & Sukaryo & Tidak & Mampu & Terberdayakan \\
\hline 7 & Paito Amorogo & - & - & - \\
\hline
\end{tabular}

Sumber: Data primer (diolah)

Pada tabel 6 di atas terlihat empat informan yang merupakan mualaf Tengger terberdayakan karena mampu membeli kendaraan bermotor setelah menjadi mualaf dan menerima pemberdayaan serta pembinaan dari LAZNAS BMH. 3 informan yang merupakan mualaf suku Tengger tidak memberi keterangan mengenai mampu atau tidak untuk memenuhi kebutuhan kendaraan bermotor.

pemenuhan kebutuhan rekreasi

Pada tabel 7 di bawah terlihat empat informan yang merupakan mualaf suku Tengger terberdayakan karena mampu memenuhi kebutuhan rekereasi setelah menjadi mualaf dan mendapatkan pemberdayaan dan pembinaan dari LAZNAS BMH. tiga informan yang merupakan mualaf suku Tengger tidak terberdayakan karena tidak mampu untuk memenuhi kebutuhan rekreasi setelah 
mendapatkan pemberdayaan dan pembinaan dari LAZNAS BMH.

Tabel 7.

Pemenuhan Kebutuhan Rekreasi Mualaf Suku Tengger

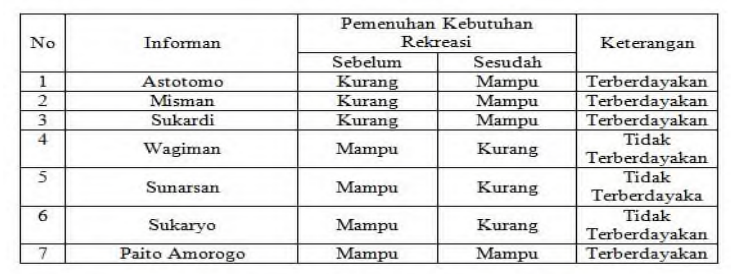

Sumber: Data Primer (diolah)

Berikut tabel rangkuman mengenai indikator keberhasilan pemberdayaan ekonomi mualaf suku Tengger oleh LAZNAS BMH

Tabel 8.

Rangkuman Faktor Keberhasilan Peran

LAZNAS BMH dalam Pemberdayaan Ekonomi Mualaf Tengger

\begin{tabular}{|c|c|c|c|c|c|c|c|}
\hline & Ibadah & Bertetangga & $\begin{array}{c}\text { Makan } \\
\text { dan } \\
\text { Minum }\end{array}$ & $\begin{array}{c}\text { Tempat } \\
\text { Tinggal }\end{array}$ & Pendidikan & Kendaraan & Rekreasi \\
\hline Astotomo & $\mathrm{V}$ & $\mathrm{V}$ & $\mathrm{V}$ & $\mathrm{V}$ & $\mathrm{X}$ & $\mathrm{V}$ & $\mathrm{V}$ \\
\hline Misman & $\mathrm{V}$ & $\mathrm{V}$ & $\mathrm{V}$ & $\mathrm{V}$ & $\mathrm{V}$ & $\mathrm{V}$ & $\mathrm{V}$ \\
\hline Sukardi & $\mathrm{V}$ & $\mathrm{V}$ & $\mathrm{V}$ & $\mathrm{V}$ & $\mathrm{X}$ & $\mathrm{V}$ & $\mathrm{V}$ \\
\hline Wagiman & $\mathrm{V}$ & $\mathrm{V}$ & $\mathrm{V}$ & $\mathrm{V}$ & $\mathrm{X}$ & - & $\mathrm{X}$ \\
\hline Sunarsan & $\mathrm{V}$ & $\mathrm{V}$ & $\mathrm{V}$ & $\mathrm{V}$ & $\mathrm{X}$ & - & $\mathrm{X}$ \\
\hline Sukaryo & $\mathrm{V}$ & $\mathrm{V}$ & $\mathrm{V}$ & $\mathrm{V}$ & $\mathrm{X}$ & $\mathrm{V}$ & $\mathrm{X}$ \\
\hline $\begin{array}{c}\text { Paito } \\
\text { Amorogo }\end{array}$ & $\mathrm{V}$ & $\mathrm{V}$ & $\mathrm{V}$ & $\mathrm{V}$ & $\mathrm{X}$ & - & $\mathrm{V}$ \\
\hline
\end{tabular}

Sumber: Data Primer (diolah)

$$
\begin{aligned}
& \begin{aligned}
& \text { Keterangan: } \\
& \mathrm{V}=\text { Terpenuhi } \\
& \mathrm{X}=\text { Tidak Terpenuhi } \\
&-\quad=\text { Tidak Menjawab }
\end{aligned}
\end{aligned}
$$

\section{SIMPULAN}

Simpulan yang dapat diambil dari pembahasan hasil penelitian ini adalah Berdasarkan hasil dan pembahasan penelitian tersebut, dapat ditarik kesimpulan sebagai berikut:

1) Lembaga Amil Zakat Nasional (LAZNAS) Baitul Maal Hidayahtullah berperan terhadap pemberdayaan mualaf Tengger di desa Argosari. hal tersebut terlihat dari 6 dari 7 indikator terpenuhi. 6 indikator tersebut yaitu pemenuhan ibadah, pemenuhan hubungan bertetangga, pemenuhan kebutuhan makan dan minum, pemenuhan kebutuhan tempat tinggal, pemenuhan kebutuhan kendaraan, dan pemenuhan kebutuhan rekreasi.

2) Pemberdayaan mualaf Tengger oleh LAZNAS BMH selain berdampak ekonomi juga berdampak semakin kuat akidah mualaf Tengger dalam Islam.

3) Dalam proses pemberdayaan mualaf Tengger Lembaga Amil Zakat Nasional (LAZNAS) Baitul Maal Hidayahtullah membutuhkan stakeholder. Stakeholder yang diajak kerjasama oleh LAZNAS BMH yaitu pemerintah desa dan masyarakat Tengger

4) LAZNAS BMH dalam menjalankan program pemberdayaan mualaf Tengger di desa Argosari menugaskan Da'i tinggal desa Argosari untuk menjalankan berbagai program pemberdayaan yang digagas dan diprakasai oleh LAZNAS BMH. berbagai program pemberdayaan mualaf Tengger di desa Argosari yang dilakukan oleh LAZNAS BMH meliputi 4 aspek besar. 4 Aspek besar itu yaitu Kegiatan sosial, Infrastruktur dakwah untuk membantu kegiatan dakwah, Penguatan Sumber Daya Manusia (SDM), dan Penguatan Ekonomi.

Saran yang direkomendasikan setelah melakukan penelitian ini adalah sebagai berikut: 
1) Bagi Lembaga Amil Zakat Nasional (LAZNAS) Baitul Maal Hidayahtullah (BMH), agar dalam menjalankan pemberdayaan mualaf Tengger di desa Argosari merangkul akademisi dari perguruan tinggi agar dapat membantu dalam konsep-konsep secara idealis-normatif yang diasumsikan paling efektif dalam pemberdayaan mualaf Tengger dengan mempertimbangkan keadaan lapangan dan kapasitas LAZNAS BMH.

2) Bagi Pemerintah Kabupaten Lumajang, sebagai pemangku kebijakan dalam kabupaten Lumajang agar membangun fasilitas pendidikan yang layak dan menempatkan guru-guru yang berkompeten agar pendidikan di desa Argosari dapat berkembang karena kualitas Sumber Daya Manusia (SDM) desa Argosari sangat rendah.

3) Bagi Peneliti Selanjutnya, diharapkan meneliti lagi secara komprehensif tentang pemberdayaan di desa Argosari karena pendirian pondok Pesanteran Agro Hidayahtullah masih belum selesai dibangun dan diharpakan juga melakukan penelitian secara komprehensif mengenai ekonomi Islam di pedesaan karena perkembangan ekonomi islam dapat berkembang secara cepat di daerah pedesaan sehinggaa dengan diteliti lebih komprehensif maka ekonomi Islam dapat mengembangkan dan diterapkan secara Kaffah serta merata di seluruh pelosok Indonesia.

\section{DAFTAR PUSTAKA}

Al-Utsaimin, Muhammad Shalih. 2012. Ensiklopedi Zakat. Jakarta: Pustaka asSunnah

Badan Pusat Statistik. 2011. Penduduk Indonesia Menurut Provinsi 1971, 1980, 1990, 1995, 2000, dan 2010. Jakarta: BPS

Hafidhuddin, Didin. 2004. Zakat Dalam Perekonomian Modern. Jakarta: Gema Insani

Kementrian Agama RI. 2012. Al-Qur'an Transliterasi Perkata dan Terjemahan Perkata. Bekasi: Cipta Bagus Segara

Mardikanto, Totok dan Poerwoko Soebiato. 2015. Pemberdayaan Masyarakat Dalam Perspektif Kebijakan Publik. Edisi Revisi. Bandung: Alfabeta

Moleong, Lexy J. 2014. Metodologi Penelitian Kualitatif: Edisi Revisi. Bandung: PT Remaja Rosdakarya

Qardawi, Yusuf. 2011. Hukum Zakat. Bogor: Pustaka Litera AntarNusa

Ryandono, Muhammad Nafik Hadi. 2008. Ekonomi ZISWAQ (Zakat, Infaq, Shadaqah, dan Waqaf). Surabaya: Ifdi dan Cenforis

Sabiq, Sayyid. 2008. Fikih Sunnah.. Jakarta: Cakrawala Publishing

Tjiptoherianto dkk. 1988. Islam dan Kemiskinan. Bandung: Penerbit Pustaka

Undang-Undang Nomor 23 Tahun 2011

Wibisono, Yusuf. 2015. Mengelola Zakat Indonesia Diskursus Pengelolaan Zakat Nasional dari Rezim Undang-Undang Nomor 38 Tahun 1999 ke Rezim Undang-Undang Nomor 23 Tahun 2011. Jakarta: Prenadamedia Group

Yin, Robert K. 2003. Appliations of Case Study Research: Second Edition. New Delhi: Sage Publications India Pvt. Ltd

Zuhri, Damanhuri. 2015. Pembinaan Mualaf Tugas Baznas, (online), (http://www.republika.co.id/berita/duni a-islam/mualaf/15/03/02/nkitgfpembinaan-mualaf-tugas-baznas, diakses 1 Desember 2015). 